\title{
A case of a sea snake bite resulting in fatal envenoming
}

\author{
K K Vithanage ${ }^{1}$, K Thirumavalavan $^{1}$ \\ Ceylon Medical Journal 2012; 57: 174-175
}

\section{Introduction}

Sea snakes of Sri Lanka are among the most venomous snakes in the island although they have not received much attention in the last few decades. According to data from other countries, they may be more toxic than highly venomous land snakes in the island. Most sea snake species found around Sri Lanka are gentle and inoffensive and will only bite when provoked, but certain species like Astrotia stokesii and Enhydrina schistosa are known to be much more aggressive. We report a case of fatal sea snake envenoming in Sri Lanka.

\section{Case report}

A 40-year old fisherman was brought with severe myalgia six hours following a sea snake bite. He was bitten by the snake, an unprovoked bite while bathing in the sea at Poruthota, Negombo. Following the bite he noticed transient bleeding from the site with no associated pain. Additionally he had trismus and limb weakness. On examination there was bilateral partial ptosis with ophthalmoplegia and flaccid quadriparesis. Bite site did not reveal typical fang marks and instead there was mild erythema with few haemorrhagic spots. He was anuric upon catheterisation and with fluid challenge produced maroon coloured urine.

His initial investigations revealed neutrophil leucocytosis with a white cell count of $17.5 \times 10^{6} / \mu \mathrm{l}, \mathrm{CPK}$ of $29700 \mathrm{U} / \mathrm{L}$ and urine was positive for myoglobin. His renal functions, serum electrolytes and coagulation tests were normal. However, the urine output progressively diminished and therefore he underwent haemodialysis during which the patient developed cardiorespiratory arrest and succumbed despite resuscitation.

At the time of the bite which was unprovoked, the snake was caught by his fellow men. Its head was crushed by the time we arrived at the scene, depriving us from definitive macroscopic identification of the snake. It was $2 \mathrm{~m}$ long and was identified subsequently as Enhydrina schistosa by the experts in the field.

\section{Discussion}

Sea snakes, venomous elapid snakes that inhabit marine environments, are the most abundant and widely dispersed group of poisonous reptiles in the world. They comprise approximately 70 species, 50 of which are members of the family Hydrophiidae [1]. Snakes of at least five distinct lineages inhabit the marine environment [2]. The first information about the species composition of sea snakes of Sri Lanka was published in 1921 [2].

The Sri Lankan species range in size from $\sim 75 \mathrm{~cm}$ Pelamis platurus to the $\sim 300 \mathrm{~cm}$ Hydrophis spiralis, which is probably the longest sea snake in the world. The coastal and deep sea waters of Sri Lanka harbours ideal habitats for sea snakes. Their venoms are more toxic than those of land snakes [3]. Enhydrina schistosa was the most aggressive, biting readily when venom extraction was attempted [4]. Nearly $80 \%$ of sea snake bites fail to produce significant envenomation, and bites may be inconspicuous, painless, and free of oedema [1,4]. Usually, little or no swelling is involved, and it is rare for any nearby lymph nodes to be affected though this was found in the first authenticated case of sea-snake envenoming in Sri Lanka [5].

Though sea snake bites are known to occur following provocation, this has not been so in the Sri Lankan context where bites have occurred in unprovoked circumstances as in this case. As described in the literature this patient had evidence of myotoxicity and neurotoxicity without any derangement in the coagulation. The primary neurotoxin causes peripheral paralysis by competitively binding to postsynaptic nicotinic acetylcholine receptors at the neuromuscular junction. Potent myotoxins account for the significant muscle necrosis, with consequent myoglobinuria.

Antivenom administration is indicated for any patient with signs of envenomation. The agent of choice is polyvalent sea snake antivenom. Sri Lanka being an island is at high risk of sea snake bite exposure although very few cases have been reported as yet. We do not have sea snake antivenom and the available land snake antivenom is not effective for sea snake envenomation.

\section{Acknowledgements}

We thank Professor S A M Kularatne and Mr. A De Silva for assisting us to identify the snake.

${ }^{1}$ Medical Ward, Colombo North Teaching Hospital, Ragama, Sri Lanka.

Correspondence: KKV, e-mail: <kumarangie@gmail.com>. Received 17 April and revised version accepted 28 July 2012. Competing interests: none declared. 


\section{References}

1. Papanagnou DOS. Sea Snake Envenomation. (http:// emedicine.medscape.com/article/771804-overview)

2. Somaweera R, Somaweera N. An overview of Sri Lankan sea snakes with an annotated check list and a field key. Taprobanica 2009; 1: 43-54.

3. Senanayake MP, Ariaratnam CA, Abeywickrema S,
Belligaswatte A. Two Sri Lankan cases of identified sea snake bites, without envenoming. Toxicon 2005; 45: 861-3.

4. Fernando M, Gooneratne W. Sea-snake envenoming. Ceylon Medical Journal 1983; 28: 131-43.

5. Amarasekera N, Jayawardena A, Ariyaratnam A, Hewage UC, de Silva A. Bite of a sea snake (Hydrophis spiralis): a case report from Sri Lanka. The Journal of Tropical Medicine and Hygiene 1994; 97:195-8.

\title{
Bilateral psoas abscess in a renal transplant patient
}

\author{
A S Badurdeen ${ }^{1}$, P N Rajakrishna'1, H M N J Herath ${ }^{1}$, A W M Wazil', N Nanayakkara' \\ Ceylon Medical Journal 2012; 57: 175-176
}

\section{Introduction}

Psoas abscess is a rare complication of transplantation. There is often delay in diagnosis as its relative infrequency and the non specific signs and symptoms. We present a case of bilateral psoas abscessess developing two months after a living donor kidney transplant.

\section{Case report}

A 51-year old male with type 2 diabetes mellitus who underwent living donor kidney transplantation two months earlier was admitted with low back pain, general ill health, and a $5 \mathrm{~kg}$ weight loss over one month. Immediate post transplant period was complicated by an acute tubular necrosis of the graft and he was intermittently dialysed via a femoral line for ten days, as his shunt flow was inadequate. The post transplant course was otherwise uncomplicated, with allograft function returning to normal in two weeks. He was given cyclosporin, mycophenolate mofetil, and prednisolone. On examination, he had bilateral flank tenderness and a normal gait. Neurologically the lower limbs were normal. His oral temperature was $37.4^{\circ} \mathrm{C}$, blood pressure was 110/80 $\mathrm{mm} \mathrm{Hg}$ and pulse rate was 94/ $\min$.

He had a white blood cell count of $27 \times 10^{6} / \mu$ l with $83 \%$ neutrophils, an erythrocyte sedimentation rate of 97 $\mathrm{mm} /$ hour, a C-reactive protein level of $31.7 \mathrm{mg} / \mathrm{dl}$ and a serum creatinine level of $10^{9} \mu \mathrm{mol} / \mathrm{L}$. After the initial USSAbdomen, computed tomography imaging of his pelvis demonstrated bilateral psoas abscessess, left measuring $10 \mathrm{~cm} \times 7 \mathrm{~cm}$ and right $7 \mathrm{~cm} \times 5 \mathrm{~cm}$ (Figures 1 and 2) without any evidence of intervertebral disc involvement. The abscesses were drained initially under ultrasound guidance followed by open surgery due to poor response. Staphylococcus aureus was isolated from the pus culture. Anaerobic cultures and Mycobacterium tuberculosis were negative. Blood cultures were also negative. He was treated with intravenous meropenum cloxacillin. After six weeks of oral cloxacillin treatment erythrocyte sedimentation rate was $18 \mathrm{~mm} / \mathrm{hr}$ and C-reactive protein level was $1.7 \mathrm{mg} / \mathrm{dl}$. No relapses have occurred more than three months after completion of treatment.

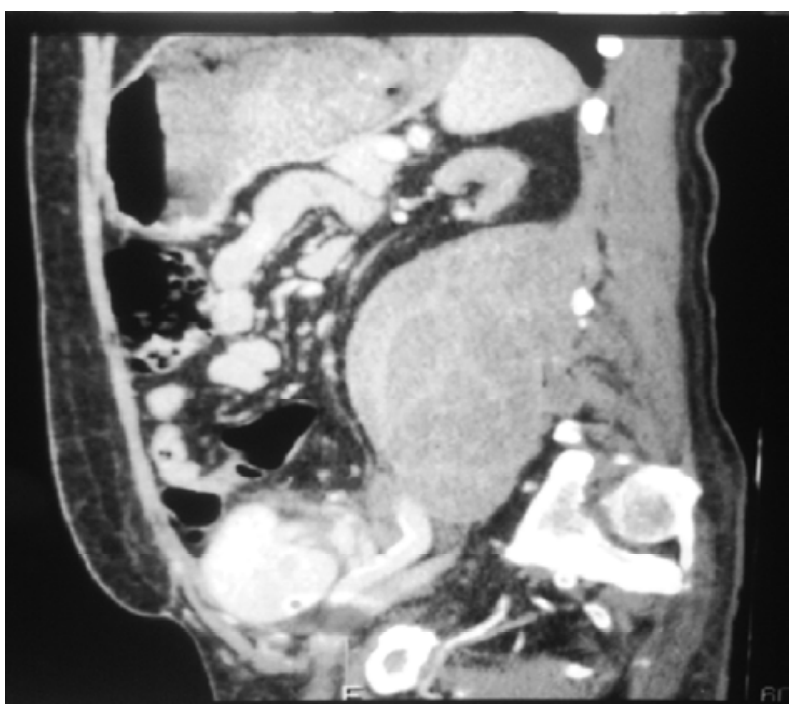

Figure 1. Coronal section of psoas abscess.

\section{${ }^{1}$ Teaching Hospital, Kandy, Sri Lanka.}

Correspondence: ASB, e-mail: <sadathba@gmail.com>. Received 12 March and revised version accepted 28 July 2012. Competing interests: none declared. 